\title{
[SOBRE] JOSÉ-ALBERTO MARQUES
}

Ernesto Manuel de Melo e Castro*

RESUMO: Texto inicialmente publicado no Jornal de Letras, Artes e Ideias, dia 7 de Dezembro de 1992, com leituras de várias obras de José-Alberto Marques, onde se inclui uma leitura dos Homeóstatos.

Palavras-chave: Homeóstatos. José-Alberto Marques. Poesia Experimental Portuguesa.

\section{Nota pessoal, mas não tanto...}

Certa vez, um editor a quem eu propusera a publicação de um livro de poemas (seguramente no intuito de desencorajar-me) respondeu que sim, publicaria o livro, mas só daí a dois anos, ao que eu logo retorqui: - Está bem, espero que a minha poesia ainda seja legível daqui a dois anos! Vem isto a propósito, não da demora da publicação de livros, mas da demora da crítica de livros, como é notoriamente o caso da revista Colóquio/Letras em que um desfasamento de dois anos ou mais entre a publicação e a respectiva crítica é tão normal que, quando a nota crítica finalmente ocorre, ela corresponde, praticamente, a um relançamento do livro, o que é óptimo... evidentemente!

No caso da presente nota crítica não são dois anos, mas apenas alguns meses, incluindo a desculpa das férias, etc. São só alguns meses que medeiam entre a publicação do último livro de José-Alberto Marques, Loendro (embora datado de 1991), mas são muitos anos em que deste poeta quase se não fala, ou não fala mesmo.

Isto parece-me, se não grave, pelo menos triste. Porque José-Alberto Marques é um

\footnotetext{
* Poeta, ensaísta e Doutor em Letras pela Universidade Católica de São Paulo. 
poeta raro, numa escala de exigência que coloca na zona fria muitos dos nomes hoje (transitoriamente) bem cotados. Essa escala é a minha. E é esse meu critério de exigência (que evidentemente não está na moda) que me leva a ficar triste com o silêncio que se abate sobre poetas como José-Alberto Marques, principalmente porque esse silêncio é um sinal do empobrecimento a que todos nós vimos estando sujeitos, em nome rigorosamente de nada. De nada, porque nada, efectivamente, pode substituir o prazer de ler um poeta de qualidade, mesmo num país, como o nosso, onde há muitos poetas (diz-se...). É que o percurso poético e a proposta de escrita de José-Alberto Marques são marcados por alguns traços bem nítidos que lhe dão um sabor único, na específica fruição das leituras que proporcionam e no enriquecimento perceptivo que consigo transportam.

\section{Uma referência a Borges}

A propósito de níveis de leitura, encontro num recente número da revista Hora de Poesia (Barcelona) o seguinte texto de Jorge Luis Borges que logo associei, intuitivamente, ao meu já longo conhecimento da poesia do José-Alberto Marques e que agora traduzo:

\footnotetext{
Enganados pela precisa forma rectangular, pelo peso, pelos símbolos tipográficos e pela ordenação das folhas, pelo complexo testemunho dos sentidos, imaginamos falaciosamente que um livro é uma coisa no espaço. Efectivamente é um acto no tempo, ou, melhor dito, uma série de actos, porque cada leitura difere, mesmo que levemente, das leituras anteriores. Já Dante falou do sentido quádruplo do seu poema; já Escoto Erígena entendia que cada versículo da Bíblia é capaz de interpretações tão infinitas como os reflexos do sol nas penas do pavão real. Todo o livro é, portanto, muitos livros.
}

Desloca-se assim para a capacidade de leitura a possibilidade infinita de ler os vários livros contidos no tempo (ou nos tempos) que o objecto livro sensorial e ilusoriamente espacial, em si comporta. Mas tal possibilidade, infinita ou não, não depende apenas do leitor. Ela deve estar embebida no próprio livro: tanto na escrita que o compõe, como até nas características físicas que o definem como objecto-livro. Isto é, há livros que são capazes de suscitar, mais do que outro, as infinitas leituras temporais neles contidas, justamente porque foram escritos para que assim acontecesse. É 
precisamente este o caso dos livros de poesia de José-Alberto Marques e muito particularmente deste, que serve de causa próxima a esta crítica (im)possível: Loendro.

\section{3 "Loendro». O que é o Loendro?}

Loendro é um pequeno livro de 32 páginas dividido anonimamente em três secções: Poesia/Poesias/Poema. Só a leitura repetida dos textos assim "disfarçados" nos revela que a sua escrita foi construída para ir além de si própria, para não parar nunca. E, no entanto, o autor deixou o seu aviso na citação de T. S. Eliot que abre o livro: "Words move, music moves / only in time; but that which is only living / can only die".

Sim, as palavras movem-se no tempo, mas é preciso um poeta para as escrever movendo-as no tempo. Essa escrita é, em José-Alberto Marques, a escrita das repetições sucessivas, dos paralelismos intermináveis que acrescentam sempre a substância complexa do poema, como se de uma matéria orgânica se tratasse. Um exemplo é logo o início do primeiro poema:

\section{O loendro}

As margens de

o loendro

As súbitas as margens de o loendro

As águas de máguas em as súbitas as margens de o loendro

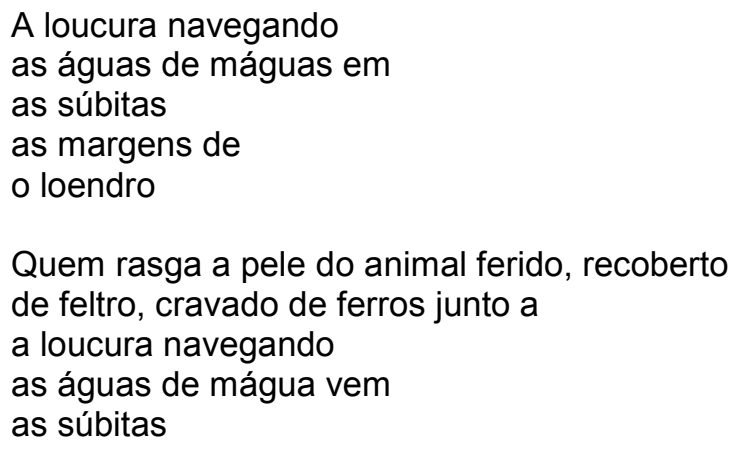


as margens de

o loendro

O loureiro-rosa

... e o poema prossegue ganhando complexidade e novas possibilidades infinitas de leitura, apoiando-se primeiro, subtilmente, na polissemia de loendro planta e de loendro rio (simultaneamente pode estar na margem e ser a margem). Mas também na falsa transformação de "loendro" em "loureiro-rosa", que botanicamente podem ser a mesma planta, mas que no poema são, distintamente, imagens diferentes. Esse loendro/loureiro-rosa será sucessivamente transformado ao longo do poema em "rosa-loura" (flor? mulher?) e em "pássaro-lira", em Düsseldorf, em Marselha e na Índia, o que equivale a dizer, estendendo-se a vários-todos-os-locais onde "com sabor, saborosamente viajando a morte e o seu espanto, abrindo portas e janelas numa visita ao espelho e à memória, descendo ruas, o peito ao longo das avenidas...».

José-Alberto Marques, já num extraordinário texto de 1966 (romance? poema em prosa?) intitulado Sala Hipóstila (Assírio \& Alvim, 1973), desenvolvera ao longo de 123 páginas as subtis e encantatórias metamorfoses de um texto construído metonímica e repetitivamente no esquema de "Quem conta um conto, acrescenta-Ihe um ponto». $E$, assim partindo de um núcleo textual inicial que ele próprio se desenvolve repetitivamente, constituido apenas por um substantivo e o seu artigo definido, $O$ girassol, atinge a complexidade de parágrafos de várias páginas e até de capítulos inteiros. "O girassol a voz do girassol a sombra da voz do girassol a serpente que dá sombra na voz do girassol o sol que cobre a serpente que dá sombra na voz do girassol"... e assim por diante!

Tanto no poema Loendro (1989) como em Sala Hipóstila (1966), trata-se efectivamente de um processo de escrita que inclui em si próprio um processo de auto-releitura, envolvendo a criação de sobrecargas metafóricas, de transformações mágicas geradoras de um clima de repetição infinita que conduz o leitor a circular, movendo-se no tempo sempre por lugares diferentes mas caleidoscopicamente reconhecíveis, mas abismais. 
Não é por acaso que José-Alberto Marques coloca no início de Sala Hipóstila uma citação de Borges: "Costumo regressar sempre ao Eterno Retorno".

\section{Os Homeóstatos}

A homeostasia é constituída pelos mecanismos biológicos de conservação de um ambiente interno constante. José-Alberto Marques deu o insólito título de Homeóstatos a uma belíssima série de dez poemas visuais létricos publicados em Operação-1 em 1967. Neles, uma linha inicial se decompõe através de disseminações no espaço da página, até que, na última linha, os signos se organizam, reconstituindo o ambiente interno do organismo vivo que é o poema. Quer neste processo visual, quer em Sala Hipóstila, quer agora em Loendro se colocam, embora de um modo diferente, os problemas de releitura implicados na construção de um tempo interno que assegura a coesão do texto: o Eterno Retorno para Borges, a homeostasia para José-Alberto Marques.

É que para este, o texto é predominantemente um organismo, ou seja, um conjunto de partes que trabalham todos para o mesmo fim: a sua automanutenção e até a sua reprodução. A homeostasia torna-se, assim, para este poeta, uma metáfora da própria especificidade da poesia.

\section{Um livro é vários}

Percorrendo a bibliografia poética de José-Alberto Marques verificamos que, ao contrário de muitos autores que escrevem sempre o mesmo livro, ele escreveu em cada livro, vários. Isto equivale a dizer que uma das características desta poética é a plurissignificação e que a organicidade que nela se materializa é a da metamorfose. No entanto, as transformações viram-se para dentro do próprio texto e é nesse mesmo texto que se incrustam os vários níveis de fruição que a leitura vai sucessivamente revelando ao leitor.

O primeiro desses níveis é uma aparente pele lírica e até bucólica dada por abundantes e repetidas imagens de origem botânica, plantas e flores, como se de um 
jardim se tratasse. Note-se desde logo o loendro/loureiro-rosa e o girassol de Sala Hipóstila. Um levantamento dessas imagens seria imenso e quase interminável. Mas logo o nível existencial contamina o bucolismo superficial transformando-o num amargo lirismo em que as referências autobiográficas (?) caóticas mal ocultam a presença do temor, do terror, do amor e da morte:

\footnotetext{
Para abrir o sol com o terror e a boca com o grito

Temo pela chuva depois de eu morrer

Temo pelo fogo, por ele, que arde

in Loendro
}

Mas tudo isto se passa ao nível do distanciamento inicial que um grau elevado de consciência do texto proporciona. É que o nível da construção literária é inevitável para que haja literatura. Mas a informação que constitui a bagagem do poeta não pode, no entanto, restringir-se a essas mesmas referências literárias. Assim, JoséAlberto Marques recorre a outras ciências, tal como a já referida biologia e também a recursos paralelísticos que tanto podem ter origem nos cancioneiros medievais e na tradição da poesia popular, como na teoria matemática da iteracção!

Pode até dizer-se ser ele o reinventor actual, na Poesia Portuguesa, da repetição sistemática como oposta da repetição caótica dos surrealistas, processo que tendo óbvias relações com exercícios ginásticos e de bailado o poeta realiza no poema cénico "Flexões Reflexões", de 1985. Ora, a repetição sistemática é um processo de multiplicação polissémica de uma imagem até à sua transformação noutra imagem, provavelmente igual mas agora já dada e percebida como diferente.

Por seu lado, o que é uma sala hipóstila? É uma sala cujo tecto é sustentado por colunas, o que cria uma percepção múltipla na divisão do espaço da sala com efeitos de infinito, tal como acontece por exemplo na Mesquita de Córdova. Um sistema visual especular, ao modo barroco, pode também divisar-se em muitos poemas principalmente no livro Hoje. Mas, do qual cito o seguinte poema:

não recuso a janela o vinho

não recuso abuso dos teus dedos 


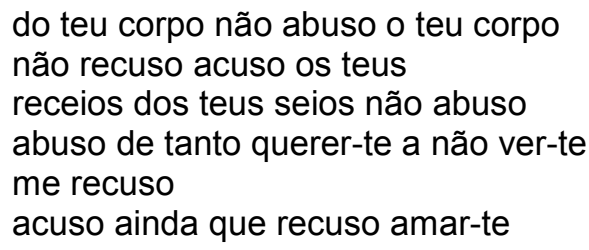

\section{Do ponto ao final}

Este é o título da "narrativa" que constitui uma radical proposta de metonímia visual (1980). Entre um primeiro texto aparentemente arbitrário e totalmente casual e o último texto caótico e certamente sem o sentido discernível, encontram-se vinte e oito páginas de signos não verbais que de página a página se estruturam sequencialmente, abrindo-se à leitura visual de um modo contraditoriamente coerente. Aqui a metáfora é nula. A escrita é o que nós lermos nela. Do ponto ao final, mas certamente ainda mais além ...

\section{[ABOUT] JOSÉ-ALBERTO MARQUES}

ABSTRACT: Text originally published in Jornal de Letras, Artes e Ideias, Dezembro 7, 1992, about several of José-Alberto Marques' works, including Homeóstatos.

Keywords: Homeóstatos. José-Alberto Marques. Portuguese Experimental Poetry.

Recebido em: 19/05/2016.

Aceito em: 15/06/2016. 